Nordic Concrete Research - Publ. No. NCR 61 - ISSUE 2 / 2019 - Article 4, pp. 53-78

\begin{tabular}{|c|c|}
\hline$S$ sciendo & 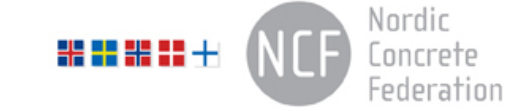 \\
\hline \multirow{2}{*}{$\begin{array}{l}\text { (C) Article authors. This is an open access article distributed under } \\
\text { the Creative Commons Attribution-NonCommercial-NoDerivs } \\
\text { licens. (http://creaticecommons.org/licenses/by.nc-nd/3.0/). }\end{array}$} & ISSN online $2545-2819$ \\
\hline & ISSN print $\quad 0800-6377$ \\
\hline \multirow{3}{*}{ DOI: $10.2478 /$ ncr-2019-0017 } & Received: Sept. 18, 2019 \\
\hline & Revision received: Nov. 6, 2019 \\
\hline & Accepted: Nov. 6, 2019 \\
\hline
\end{tabular}

\title{
Topological and Size Optimization of RC Beam Bridges: An Automated Design Approach for Cost Effective and Environmental Friendly Solutions
}

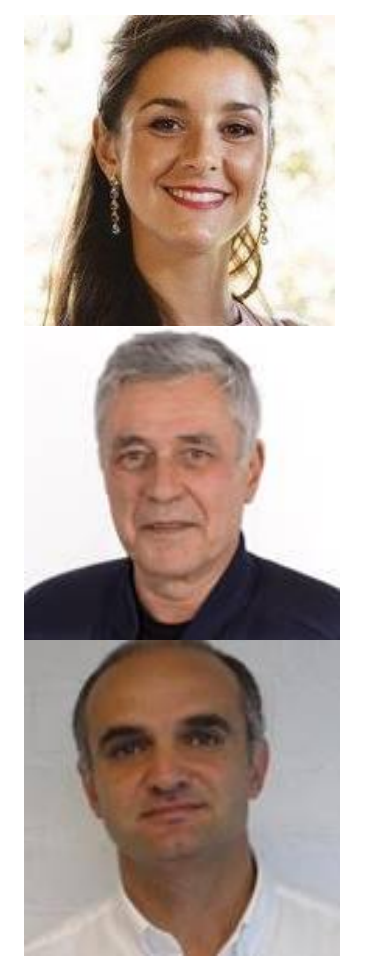

\author{
Elisa Khouri Chalouhi, MSc Degree \\ Birth date: 1991-09-14 \\ $\mathrm{PhD}$ student at the Division of Structural Engineering and \\ Bridges, KTH Royal Institute of Technology, Brinellvägen 23, \\ SE-100 44, Stockholm \\ elisakc@kth.se
}

Costin Pacoste - PhD degree

Adjunct Professor of the Division of Structural Engineering and Bridges, KTH Royal Institute of Technology, Brinellvägen 23, SE-100 44, Stockholm. Chief Technical Officer, ELU Konsult, Valhallavägen 117, 11531 Stockholm

costin.pacoste@byv.kth.se

Raid Karoumi - PhD degree

Professor and Head of the Division of Structural Engineering and Bridges, KTH Royal Institute of Technology, Brinellvägen 23, SE-100 44, Stockholm

raid.karoumi@byv.kth.se

\begin{abstract}
This work presents a procedure for the automated design and optimization of reinforced concrete beam bridges. The aim is to find solutions that minimize the investment cost and the environmental impact of the bridge. The complete structure is optimized including: number of spans, pier locations, pier-deck connections and deck dimensions. A detailed design of the deck reinforcement is included as well. Furthermore, constructability is considered and quantified within the investment cost to avoid a merely theoretical optimization. Genetic Algorithm (GA) and Pattern Search (PS) optimization algorithms are used. To reduce the computational time and make the procedure more user-friendly, a memory system is integrated and a modified version of GA is developed. In this paper, the proposed procedure is applied to re-design an existing bridge
\end{abstract}


originally designed according to Eurocodes by an experienced engineer in 2013. Savings of 10$15 \%$ for both investment cost and environmental impact have been obtained. Finally, the proposed procedure has been applied to several alternatives with different total bridge lengths to suggest the optimal number of spans for a given total bridge length.

Key words: Structural optimization, automated design, beam bridges, environmental impact, investment cost.

1.

\section{INTRODUCTION}

1.1

\section{General}

The most used design approach for civil engineering structures is a trial and error procedure; the designer chooses an initial configuration, tests it and changes it until all design requirements (serviceability, safety, durability, etc.) are met. Such a procedure has been used for decades in all engineering fields; however, it is time consuming and eventually leads to a feasible solution, while several better ones could be found. Indeed, safety is not the only requirement that the construction sector has to meet. Buildings and construction account for $39 \%$ of energy-related $\mathrm{CO}_{2}$ emissions [1]. In particular, concerning concrete structures, the cement industry by itself is responsible for around $5 \%$ of the global emissions of $\mathrm{CO}_{2}$ [2]. Moreover, the economic burden of important infrastructures such as bridges is not negligible. Therefore, together with safety, environmental impact and investment cost should be decisive factors for the selection of a structural solution. The current design practise paired with years of experience can give rise to rules-of-thumbs for preliminary design [3] that could result in a good solution, but cannot guarantee the cost and emission-efficiency of the structure. To do so, several different solutions should be considered and compared in order to choose the optimal one. Thus, structural optimization with respect to environmental impact and cost has become of major interest in the last decades. The academic world has been continuously active in the field of structural optimization of bridges from 1970 [4-6] until today. Topology optimization has been applied to identify the best material layout for several types of bridges [7-8]. When the attention is focused on one particular bridge type, size optimization is a common area of research; some works consider also materials as design variable, while few works optimize the structural configuration. In particular, reinforced concrete (RC) portal frame bridges [9-11], cable stayed bridges [12-14] and suspension bridges [15-17] have been object of many researches. Concerning beam bridges, the main object of study has been the deck. Size optimization with the aim of minimizing cost has been performed for prestressed concrete (PC) [18-19], RC [20-21] and steel-concrete composite decks [22]. Not only cost, but also $\mathrm{CO}_{2}$ emissions have been minimized for PC [23-24] and steel-concrete composite decks [25]. Finally, an attempt to consider the structural system in the optimization has been made in [26]: a PC bridge is cost optimized by selecting the optimal number of spans, the number of girders and deck dimensions, assuming that the superstructure consists of a series of adjacent simply supported girders.

Even though the academic world has been active in the field of structural optimization for many decades, such techniques have not replaced the traditional design procedure yet. Pedro et al. [22] identify the reason for this in the constructive feasibility of the optimal solution. Cost optimization in literature mainly deals only with material cost. However, labour cost, time needed to erect the structure and formwork play an important role in the economy of cast in place structures [27]. 
Moreover, most of the studies optimize one component of the structure (e.g. deck); system optimization including structural configuration and component sizes is rare [28]. Concerning continuous $\mathrm{RC}$ beam bridges, no article in literature has been found dealing with the optimization of the entire bridge including both the structural configuration and sizes, to the best of the authors' knowledge. Finally, to apply structural optimization in bridge design, computational time has to be kept limited without losing accuracy. Some techniques are proposed in [22] and [29].

Therefore, this work aims to cover the gap between theoretical studies and actual application by proposing a new design and optimization approach for $\mathrm{RC}$ beam bridges. Given the soil morphology and the two points the bridge has to connect, this method produces a complete optimal solution including: number of spans, pier locations, pier-deck connections, deck crosssection dimensions and corresponding reinforcement amount and layout. Investment cost or environmental impact of the entire bridge can be minimized. In particular, in the investment cost calculation material cost is considered together with labour cost, which is computed as a function of the time needed to construct each bridge component. It this way, optimal solutions inappropriate for actual construction are avoided. Genetic Algorithm (GA) and Pattern Search (PS) are used as optimization algorithms. Finally, to reduce the computational time and to make the procedure more user-friendly, a memory system has been integrated and a modified version of GA has been proposed.

2.

\section{METHODOLOGY}

The proposed method consists of an iterative optimization procedure divided in several modules (Figure 1).

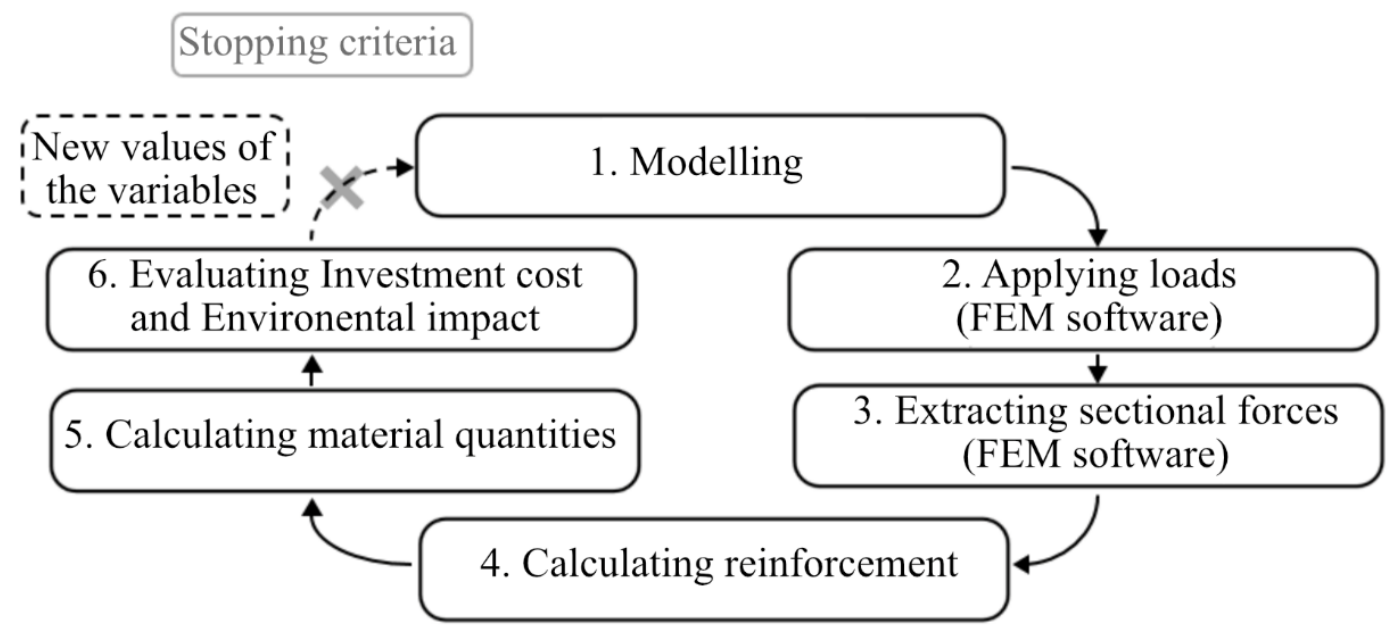

Figure 1 - Design and optimization process.

In Module 1, a set of values for the design variables that describe the three dimensional model of the bridge is assumed. At this point, an external FEM software able to handle moving traffic loads is called by the main program. In Module 2, it applies the loads and their combinations requested by Eurocode 1 [30] and in Module 3 it calculates the internal forces and moments in the bridge deck. These values are used in Module 4 to calculate the deck reinforcement required by Eurocode 2 [31] to satisfy the Ultimate Limit State (ULS) and the Serviceability Limit State (SLS). At this point the geometry of the bridge is completely defined and materials quantities can be computed 
in Module 5. Finally, in Module 6, the investment cost and the environmental impact of the bridge are calculated. Once the last module has been reached, an optimization algorithm varies the values of the design variables of Module 1 and the cycle starts again. The process stops when one of the stopping criteria of the optimization algorithm is met.

In this work, the design variables are: number of spans (user-defined admissible range), longitudinal location of intermediate piers, type of connection intermediate pier-deck and concrete deck dimensions (user-defined number of design cross-sections per span). The total number of variables is, therefore, function of the number of spans. Since optimization algorithms require a fixed number of design variables, it is not possible to optimize all variables at the same time. Therefore, the approach proposed in [32] is adopted: the problem is divided in two consecutive levels and several sub-levels as shown in the example of Figure 2. Level 1 has the goal of optimizing the static system (i.e. number of spans, pier locations and pier-deck connection), while level 2 has the goal of optimizing the cross-section dimensions. Level 1, in turn, is divided in sublevels: one for each possible number of spans. In the example of Figure 2, four, five and six spans are analysed. Each sub-problem of level 1 is solved through the procedure of Figure 1: in particular, the deck cross-section is kept constant and with dimensions defined by the user, while the variables are the intermediate pier locations and their connections with the superstructure. At the end of level 1, the optimal static system configurations for all sub-problems are compared. The one resulting in the lowest investment cost or environmental impact is selected and used in level 2.
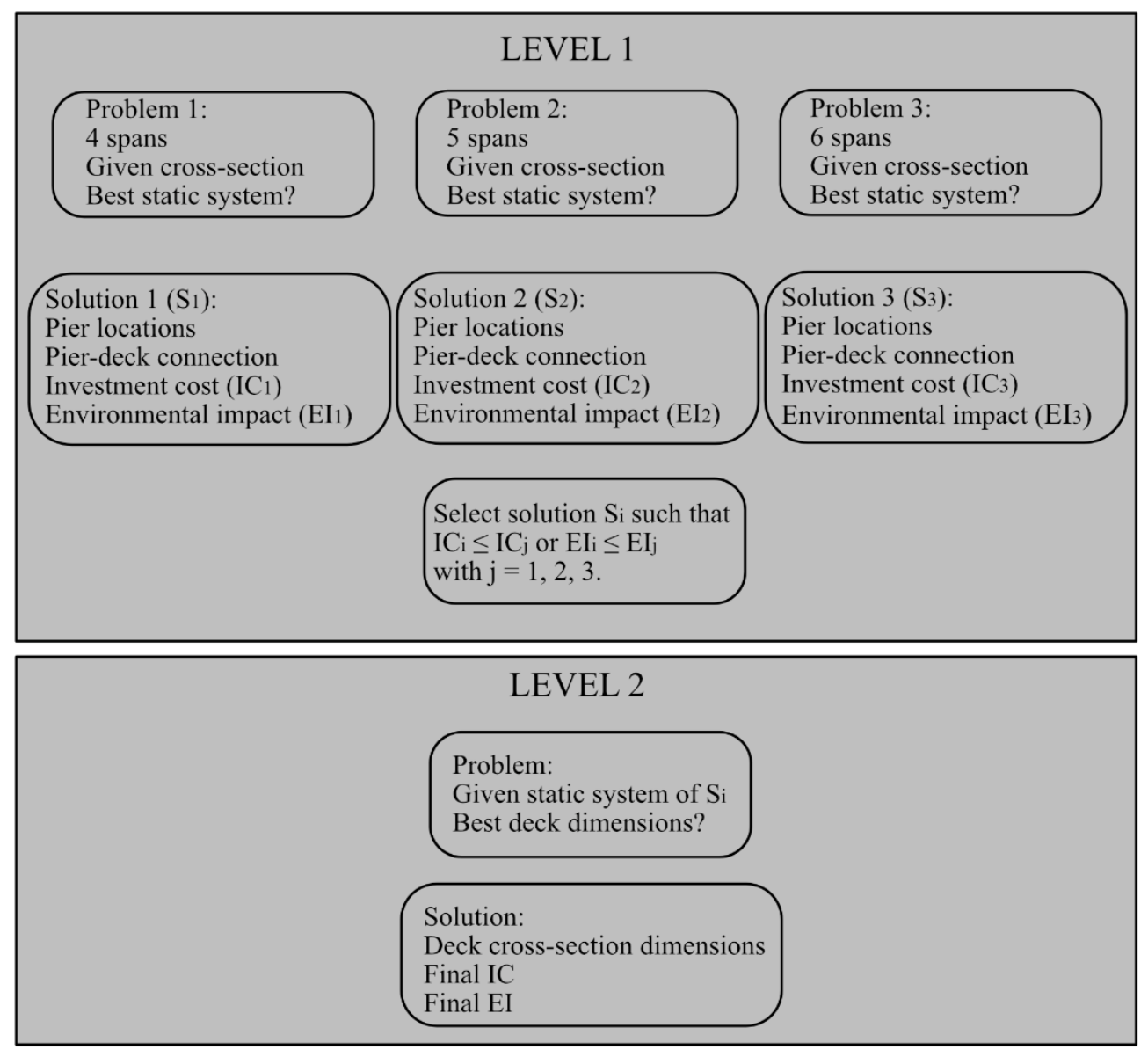

Figure 2 - Level 1 and level 2 optimization in the case of bridge with four, five and six spans. 
Also level 2 follows the procedure of Figure 1, but has all cross-sectional dimensions of the deck as design variables. Dividing the procedure in two levels not only solves the problem of varying number of variables but also allows for finding the optimal solution in a faster way by reducing the total number of variables treated simultaneously.

A software that performs the steps described above has been developed in MATLAB ${ }^{\circ}$. Concerning the FEM software for the structural analyses, any software able to handle moving traffic loads and all the load combinations requested by Eurocodes could be used in Modules 2 and 3. In the present work, a Swedish FEM software called Strip-Step 3 has been used. The calculations are made according to Hooke's law and Navier's formula. Timoshenko beam elements have been employed.

\subsection{Optimization problem}

The general mathematic formulation of a nonlinear optimization problem is that in Eq. (1) [33]:

$$
\begin{array}{lll}
\text { minimize } & f_{i}(\boldsymbol{x}), & i=1,2, \ldots, M \\
\text { subject to } & g_{j}(\boldsymbol{x}) \leq 0, & j=1,2, \ldots, J \\
& h_{k}(\boldsymbol{x})=0, & k=1,2, \ldots, K \\
\text { where } & \boldsymbol{x}=\left(x_{1}, x_{2}, \ldots, x_{d}\right) & \boldsymbol{x} \in\left[\boldsymbol{x}_{\text {min }}, \boldsymbol{x}_{\text {max }}\right] \subset \mathbb{R}^{d}
\end{array}
$$

where $f_{i}(\boldsymbol{x})$ are called objective functions, while $g_{j}(\boldsymbol{x})$ and $h_{k}(\boldsymbol{x})$ are the constraints of the problem. The vector $\boldsymbol{x}$ contains the design variables, which are the quantities the optimization algorithm can independently vary in order to minimize the objective functions. User-defined quantities needed to describe the problem are called preassigned parameters.

Design variables can be discrete or continuous based on the structural property they represent. Four categories of variables can be identified in the field of structural optimization of discrete structures: material properties, structural system topology (i.e. connections between structural members), structural system shape and structural members' size. While those belonging to the last two categories are usually continuous, the rest are discrete.

Constraints instead can be divided in two main categories: linear and nonlinear. The latter, together with linear constrain functions of two or more design variables, make constrained optimization problems more difficult to handle than unconstrained ones. To address this issue, a strategy can be to solve an equivalent unconstrained problem instead of the original constrained one using the penalty method [33]. The objective function $f(x)$, here assumed to be unique for the sake of simplicity, is replaced by the penalized objective function $\Pi(x, \mu, v)$ in Eq. (2).

$$
\Pi(\boldsymbol{x}, \boldsymbol{\mu}, \boldsymbol{v})=f(\boldsymbol{x})+P(\boldsymbol{x}, \boldsymbol{\mu}, \boldsymbol{v})
$$

The penalty term $P(\boldsymbol{x}, \boldsymbol{\mu}, \boldsymbol{v})$ has several popular definitions, among which the one in Eq. (3) [34].

$$
P(\boldsymbol{x}, \boldsymbol{\mu}, \boldsymbol{v})=\sum_{j=1}^{J} \mu_{j} H_{j}\left[g_{j}(\boldsymbol{x})\right] g_{j}^{2}(\boldsymbol{x})+\sum_{k=1}^{K} v_{k} H_{k}\left[h_{k}(\boldsymbol{x})\right] h_{k}^{2}(\boldsymbol{x})
$$

In Eq. (3), $\mu_{j}>0$ and $v_{k} \gg 1$, while the terms $H_{j}\left[g_{j}(\boldsymbol{x})\right]$ and $H_{k}\left[h_{k}(\boldsymbol{x})\right]$ are defined in Eq. (4a-b).

$$
H_{j}\left[g_{j}(x)\right]=\left\{\begin{array}{l}
0 \text { if } g_{j}(x) \leq 0, \\
1 \text { otherwise }
\end{array}\right.
$$




$$
H_{k}\left[h_{k}(\boldsymbol{x})\right]=\left\{\begin{array}{c}
0 \text { if } h_{k}(\boldsymbol{x})=0, \\
1 \text { otherwise, }
\end{array}\right.
$$

With these definitions, the penalty term is proportional to the magnitude of the constraint violations. The penalty method, however, handles the constraints issue while computing the objective function; this implies all the intermediate steps between assigning values to the design variables and computing the corresponding objective function. This entire process can be time consuming; an alternative could be to evaluate constraints as soon as the solution has been generated (values for the variable has been assigned) and discard it in case it is not feasible. Both methodologies have been used in the present work to handle different types of constraints.

\section{Numerical implementation}

At the current stage, the developed software performs a single-objective optimization using investment cost or environmental impact as fitness function. However, during the process, both values are calculated and saved.

\section{Investment cost}

The investment cost $(I C)$ of the entire bridge is computed as the sum of those of each part of the structure. For each bridge component, the investment cost is calculated by summing two contributions: material cost $(M C)$ and labour cost $(L C)$. Material cost for a specific material $(m)$ and bridge component/element $(e)$ is calculated as in Eq. (5).

$$
M C_{m}^{e}=C_{m} \times q_{m}^{e}
$$

where: $C_{m}=$ unit price for material $m$ (Appendix A), $\boldsymbol{q}_{\boldsymbol{m}}^{\boldsymbol{e}}=$ amount of material $m$ in the considered element $e$.

To properly evaluate the labour cost, several factors such as climate, weather and location of the bridge should be considered. However, when optimizing the geometry of one specific bridge, they would not change the solution. Instead, practical considerations about constructability are necessary. What determines the labour cost is the time needed to build an element, which is not only related to the amount of material, but also to the complexity of the considered element. Based on the shape, location and function of the element, the time needed to erect it can vary significantly. For instance, one element can have several shapes as for the deck in Figure 3. The reinforcement labour is of increasing difficulty going from cross-section type 1 to type 3, thus making the process longer. Therefore, labour cost for a specific material $(m)$ and bridge component/element $(e)$ is calculated as in Eq. (6).

$$
L C_{m}^{e}=C_{h} \times q_{m}^{e} \times t_{m} \times k_{m}^{e}
$$

where: $C_{h}=$ cost of labour per hour, $t_{m}=$ nominal time needed to construct/install one unit of material $m$ (Appendix B) and $k_{m}^{e}=$ constructability coefficient taking into account specific issues occurring when constructing/installing material $m$ for element $e$ (Appendix B). Since the foundation slab is the bridge component with the easiest construction procedure, it has been used as reference element. Therefore, the following interpretation is possible: $t_{m}=$ time needed to construct/install one unit of material $m$ in a slab foundation (Table 1), $k_{m}^{e}=$ ratio between the time needed to construct/install one unit of material $m$ in element $e$ and $t_{m}$. Assigning specific values to nominal time and constructability coefficients is difficult: the actual manufacturing time depends on non-quantifiable factors such as the expertise of workers. However, not including 
constructability coefficients would lead to a fictitious optimization of the structure. The amount of material would be minimized in each element and it could result in slender solution difficult to build. Values used in this work have been collected interviewing experienced designers and construction estimators from companies in Sweden.

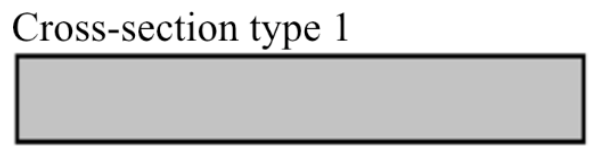

Cross-section type 2

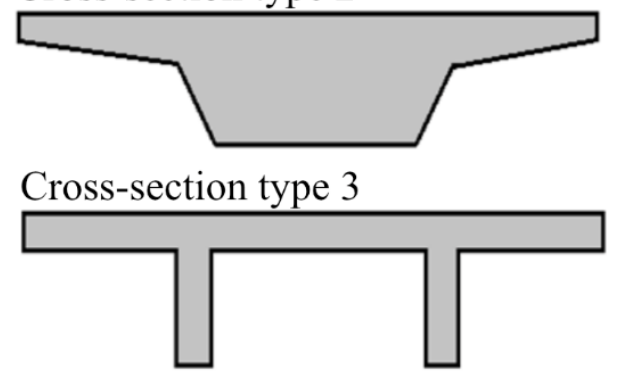

$\frac{\text { Table } 1-\text { Nominal time for material installation. }}{\text { Material } \quad \text { Nominal time } t_{m} \quad \text { Unit }}$

\begin{tabular}{ccc}
\hline Concrete & 1 & $\mathrm{~h} / \mathrm{m}^{3}$ \\
Reinforcement & 20 & $\mathrm{~h} /$ ton \\
Formwork & 1 & $\mathrm{~h} / \mathrm{m}^{2}$ \\
\hline
\end{tabular}

Figure 3 - Possible deck cross-sections.

\section{Environmental impact}

The quantification of the potential environmental impact $(E I)$ is done with the life cycle assessment (LCA) technique. ReCiPe with midpoint approach [35] is used as method for life cycle impact assessment (LCIA). Unit emissions are taken from the life cycle inventory (LCI) database Ecoinvent v.2.01 [36] used by the SimaPro software [37]. This LCI database considers the typical European technologies and averages data collected in Europe and Worldwide; moreover, it assumes the amount of recycling steel to be $37 \%$. Single material producer could use different production technologies and the amount of recycling steel could vary. Thus, different values can replace those in Table 2 in the proposed procedure.

To summarize, the idea behind LCA is that each material or energy consumption in each life cycle stage produces emissions of various types. These lead to several effects on the environment that can be classified into impact categories. Many previous studies about environmental impact of structures/bridges have considered only one impact category, i.e. climate change [3, 23 and 24]. In this work, to perform a more complete analysis, three impact categories are considered: climate change (CC), terrestrial acidification (TA) and freshwater eutrophication (FE). In order to compute one single indicator of the potential environmental impact, a further step is necessary. Weighting, indeed, consists in aggregating all total potential impacts in one single indicator. Based on society and political evaluation, a relative importance, i.e. weight, is associated to each impact category [38].

For impact category $k$, material $m$ and life cycle stage $l$, the potential impact $\left(I_{m, l}^{k}\right)$ expressed in equivalents of a certain LCI item is calculated as in Eq. (7).

$$
I_{m, l}^{k}=q_{m}^{e} \times f_{m, l}^{k}
$$

where: $q_{m}=$ consumption of material $m, f_{m, l}^{k}=$ emission of LCI item for impact category $k$ per unit material $m$ during life cycle stage $l$ (Table 2 ). The total potential impact $\left(I_{k}\right)$ in category $k$ and the total potential environmental impact (EI) are expressed by Eq. (8) and (9), respectively. 


$$
\begin{aligned}
& I_{k}=\sum_{m, l} I_{m, l}^{k} \\
& E I=\sum_{k} I_{k} \times w_{k}
\end{aligned}
$$

where: $w_{k}=$ weighting factor for impact category $k$.

\begin{tabular}{|c|c|c|c|}
\hline Material $m$ & Impact category $k$ & $f_{m, \text { production }}^{k}$ & Unit \\
\hline \multirow{3}{*}{ Concrete C25/30, CEM II } & $\mathrm{CC}$ & 261 & $\mathrm{~kg} \mathrm{CO} 2 / \mathrm{m}^{3}$ \\
\hline & TA & 0.44 & $\mathrm{~kg} \mathrm{SO}_{2} / \mathrm{m}^{3}$ \\
\hline & FE & 0.014 & $\mathrm{~kg} \mathrm{P} / \mathrm{m}^{3}$ \\
\hline \multirow{3}{*}{$\begin{array}{c}\text { Other concrete } \\
\text { (from C30/37 to C55/67, CEM II) }\end{array}$} & $\mathrm{CC}$ & 288 & $\mathrm{kgCO}_{2} / \mathrm{m}^{3}$ \\
\hline & TA & 0.50 & $\mathrm{~kg} \mathrm{SO}_{2} / \mathrm{m}^{3}$ \\
\hline & FE & 0.016 & $\mathrm{~kg} \mathrm{P} / \mathrm{m}^{3}$ \\
\hline \multirow{3}{*}{ Reinforcement A500HW } & $\mathrm{CC}$ & 1446 & $\mathrm{~kg} \mathrm{CO}_{2} /$ ton \\
\hline & TA & 4.74 & $\mathrm{~kg} \mathrm{SO}_{2} /$ ton \\
\hline & $\mathrm{FE}$ & 0.87 & $\mathrm{~kg} \mathrm{P} /$ ton \\
\hline \multirow{3}{*}{$\mathrm{RC}$ piles $\mathrm{C} 40 / 50$} & $\mathrm{CC}$ & 404 & $\mathrm{~kg} \mathrm{CO} / \mathrm{m}$ \\
\hline & TA & 0.88 & $\mathrm{~kg} \mathrm{SO}_{2} / \mathrm{m}$ \\
\hline & $\mathrm{FE}$ & 0.085 & $\mathrm{~kg} \mathrm{P} / \mathrm{m}$ \\
\hline
\end{tabular}

Table 2 - Emission of LCI items from Ecoinvent database [36].

Concerning the lifecycle stages, a cradle-to-gate approach considering only the material production phase is chosen for several reasons. First of all, previous studies [39-40] have shown that this stage is the most influential one for the studied structure. Furthermore, the aim of this work is finding the best solution, in terms of static system and dimensions, for one particular structural type (i.e. RC beam bridges). In each problem, the construction method and the maintenance schedule are assumed to be the same regardless of the solution. As a consequence, it is reasonable to expect that these phases would not significantly affect the choice of one solution instead of another. Finally, the positive effect of cement carbonation during use and demolition is not included in the calculation; it has an effect on the long term while the environmental issue needs to be promptly addressed. Moreover, due to their re-use, the production of material for temporary structures (i.e. scaffolding and formwork) is not included in the calculations. Concerning the weighting system, results of a previous study with similar aim [11] showed no great differences between the solutions obtained using two different weighting systems based on the monetary value of environmental impact: Ecotax02 [41] and Ecovalue12 [42-43]. Table 2 shows that both concrete and reinforcement steel in production phase emit much more $\mathrm{CO}_{2}$ than $\mathrm{SO}_{2}$ or $\mathrm{P}$ per unit material. As a consequence, regardless of the adopted weighting system, climate change is always the leading impact category. Therefore, Ecovalue12 is used in this work since it is more recent (Appendix C).

\section{Constraints}

When it comes to structural optimization, two main types of constraints have to be considered: structural and operational constraints. All the requirements of the Eurocodes and the national codes concerning ULS and SLS belong to the first category. In particular, in this work, the deck cross-sections are checked for crack width $(w)$, bending moment $(M)$, shear $(V)$ and torsion $(T)$. At the current stage, the focus is on cross-sections with the shape shown in Figure 4, which is simplified as in Figure 5 and Figure 6 for the ULS and SLS checks in the longitudinal direction. 


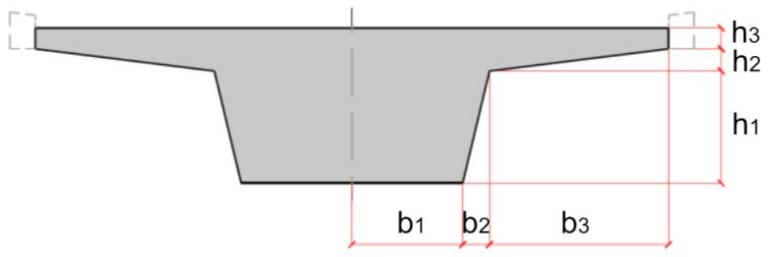

Figure 4-Cross-section of the deck.

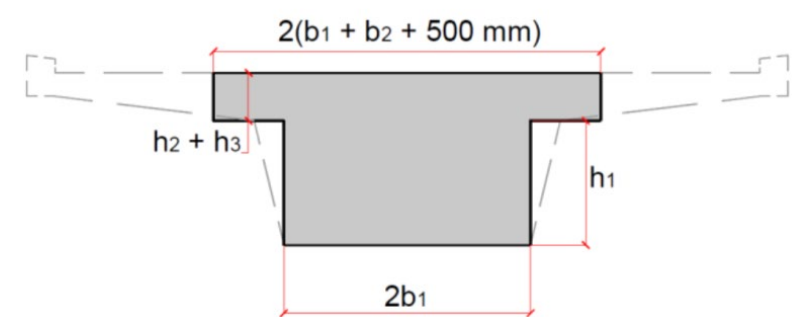

Figure 5 - Idealized cross section in ULS.

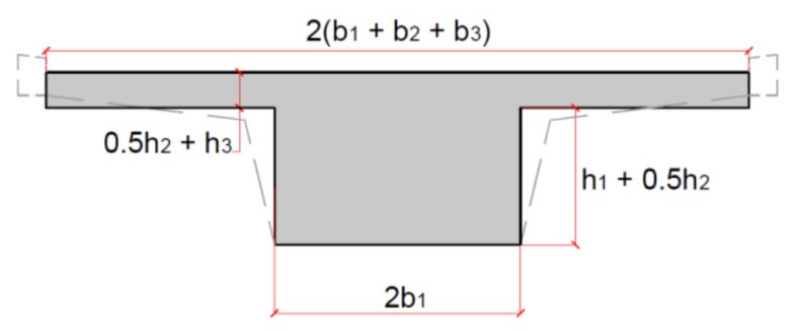

Figure 6-Idealized cross section in SLS.

Before starting the optimization, the user has to assign all dimensions of the deck cross-section $\left(h_{1}, h_{2}, h_{3}, b_{3}\right.$ and $\left.b_{2} / h_{1}\right)$, which are kept constant along the bridge during level 1 except for the web height $\left(h_{1}\right)$. In level $1, h_{l}$ is constantly updated and varies along the deck. This updating procedure is divided in two steps. In the first step, a set of values for the web height along the deck is assumed and the external FEM software uses it for the structural analysis. In the second step, the results of the structural analysis are used to find in each cross-section the minimum $h_{1}$ and the corresponding reinforcement that fulfil ULS and SLS requirements. The minimum height is then increased by $30 \%$ to account for the variations in the internal forces that are introduced by the new web heights. Whenever this value exceeds the maximum allowed by the user, the latter is used. Concerning the first step of the updating procedure, in the first cycle (i.e. iteration) of the process of Figure 1, $h_{l}$ is assumed constant along the bridge and equal to the user-defined value. In consequent iterations instead, values from the previous cycle are used as starting point for the updating procedure. Given the updated deck heights, the structural analysis is performed again and internal forces and moments are used to re-design the minimum needed reinforcement. In level 2 instead, the web height is one of the variables; therefore, the reinforcement is immediately designed for each possible solution without any updating procedure on $h_{l}$. Concerning reinforcement design, the user has to assign bars diameters, spacing and cover considering the codes and the specific bridge requirements (e.g. exposure class). The calculated reinforcement is not a theoretical value arbitrarily placed in the cross-section. Instead, it is the result of a specific bar layout which physically fits in the cross-section and guarantees the required capacity. Working in terms of total amount and ideal centre of gravity of the reinforcement has a big risk: due to the cross-section dimensions, the actual placement of the bars could lead to a different centre of gravity and a lower resistance. Thus, the need for a design that arrives to the detail of reinforcement bars layout. If the required reinforcement exceeds the maximum allowed by design codes, the latter is used instead. Infeasible cases are treated with the penalty method. Referring to Eq. (3), only the first term is considered and the magnitude of the constraint violations for each cross-section is computed as in Eq. (10),

$$
\begin{aligned}
& g_{M_{U E / L E}}(\boldsymbol{x})=M_{E d_{U E / L E}}(\boldsymbol{x}) / M_{R d_{U E / L E}}(\boldsymbol{x})-1 \\
& g_{V_{-} T}(\boldsymbol{x})=T_{E d}(\boldsymbol{x}) / T_{R d}(\boldsymbol{x})+V_{E d}(\boldsymbol{x}) / V_{R d}(\boldsymbol{x})-1
\end{aligned}
$$




$$
g_{w}(\boldsymbol{x})=w_{k}(\boldsymbol{x}) / w_{\max }(\boldsymbol{x})-1
$$

where: $\mathrm{UE} / \mathrm{LE}=$ upper edge/lower edge, $\mathrm{Ed}=$ action on the cross-section and $\mathrm{Rd}=$ resistance. $\mathrm{In}$ addition to the above mentioned constraints in the longitudinal direction, cross-sections are verified and reinforcement is designed for bending and shear of the overhang slab due to eccentric traffic. All possible locations of vehicles are considered together with the scenario of missing edge beam due to replacement. In this section, recommendations from national codes [44] and previous researches [45] have been followed.

Besides codes requirements, bridges are infrastructures built in order to cross obstacles. Therefore, there are areas where piers cannot be place and minimum vertical clearance must be guaranteed. These considerations fall in the previously mentioned category of operational constraints. In level 1, for solution with piers in infeasible regions, no structural analyses are performed: a fictitious value for the objective function is assumed, instead. To make the optimization algorithm discard such solutions in favour of feasible ones, the default value is set at one order of magnitude higher than the expected output for a feasible solution. Concerning the minimum vertical clearance, it is checked in both levels and it is treated with the penalty method. The magnitude of the constraint violation is computed as in Eq. (11).

$$
g_{V . C \cdot j}(\boldsymbol{x})=h_{\text {under }, \min _{j}} / h_{\text {under }}(\boldsymbol{x})-1
$$

where: $h_{\text {under }}=$ free height under the bridge deck and $h_{\text {under } \min _{j}}=$ minimum vertical clearance for $j$-th obstacle.

The reason for employing the penalty method for all these constraints is that they are intrinsically non-linear. The only linear constraints considered in this work are defined by the user in terms of limitations on the cross-section dimensions and on span lengths. Since in level 2 cross-section dimensions are the variables of the problem, these linear constraints are simply used to narrow down the searching space $\left[\boldsymbol{x}_{\min }, \boldsymbol{x}_{\max }\right]$. Such procedure cannot be applied to the limitation of span lengths since each length is function of two variables of level 1 (i.e. piers locations). Therefore, a linear constraint is given as input to the optimization algorithm selected for level 1 and is implemented in the form of Eq. (12).

$$
\boldsymbol{A} \times \boldsymbol{x} \leq \boldsymbol{b}
$$

Where $\boldsymbol{x}$ and $\boldsymbol{b}$ are vectors containing the variables of level 1 and minimum and maximum values for each span length, respectively. $\boldsymbol{A}$ is a matrix of 1 and 0 built such that each row of the product $\boldsymbol{A} \cdot \boldsymbol{x}$ represents the length of one of the spans.

\section{Optimization algorithms}

The selection of the type of optimization algorithm to use is influenced by the nature of the problem and of the objective function. Moreover, when it comes to practical problems, computational time plays an important role as well. The most time-consuming step of the procedure explained in section 2 is the use of a FE software application. Such a step is performed for each individual (i.e. set of tested variables) of each iteration. In level 1, it is performed twice per individual to find the deck height and design reinforcement. Considering this and the large number of variables in level 2, it is not reasonable to employ exhaustive search in this problem. Instead, using an optimization algorithm that searches in several areas of the domain to find the best solution in the shortest time is preferable. Thus, the combination of local and global search is fundamental for this problem and metaheuristic optimization algorithms could be an appropriate choice. Especially in level 1, another issue points towards this kind of algorithms: some variables are continuous (i.e. pier location), while others are discontinuous (i.e. pier-deck connection can 
only be fixed or movable). The complexity of a mixed-integer optimization problem and the consequent discontinuity of the objective function can be handled by the robustness of metaheuristic algorithms. In both level 1 and 2, the two objective functions are strictly related to the amount of materials. Concerning concrete, this amount is the result of geometric calculation based only on the variable values. Instead, the reinforcement amount is the result of a design procedure which takes into account several load scenarios and verifications. Thus, the relationship between the variables and the objective function is implicit and non-continuous. As a consequence, derivative-based optimization algorithms cannot be used for the studied problem in neither of the two levels. Moreover, in level 1, deck heights are computed with an updating procedure which starts from a set of values randomly chosen or taken from the previous iteration. These values are not related to the variable values of the current iteration. It results in the introduction of random noise in the objective function of level 1, which suggests the use of stochastic optimization algorithms. The fact that stochastic algorithms can be slower than deterministic ones is not a major problem in level 1 since the number of variables is much lower than in level 2.

For all the reasons listed above, two gradient-free optimization algorithms have been chosen: Genetic Algorithm (GA) for level 1 and Pattern Search (PS) for level 2. GA can be classified as a metaheuristic optimization algorithm that combines local and global search using randomization (i.e. stochastic). On the other hand, PS is a deterministic local search algorithm. Level 2 shows fewer difficulties than level 1 and a more straight-forward relationship variables-objective function; therefore, a local search algorithm such as PS is expected to work well. An attempt to apply GA also to level 2 has been made but it performed worse compared to PS. Furthermore, in order to make the optimization procedure faster and more user-friendly, a memory system has been integrated and GA has been customized for this specific problem. First of all, the user has to choose accuracies for the variables. At the beginning of iterations, variable values are rounded according to the accuracies. Then, results for every studied individual are saved in a continuously updated database and re-used in future iterations for individuals that differ from those in the database by less than the preassigned accuracies. In such a way, the two optimization algorithms still work with continuous instead of difficult-to-handle discrete variables but a large portion of the computational time is saved. Concerning the optimization algorithms, GA and PS provided in MATLAB ${ }^{\circledR}$ Optimization Toolbox [46] have been used. However, two customized stopping criteria have been added to GA. One of the default stopping criterion of GA consists in: i) collecting the values of the fitness function of the best individuals of all iterations, ii) computing the relative average change in the fitness function over a user-defined number of consecutive iterations, iii) comparing it with a user-defined threshold and terminate the optimization if it is lower than the threshold. Ideally, this threshold would represent the saving of the objective function that can be considered non-significant for the studied problem. However, the default stopping criterion computes the average over all consecutive iterations regardless of the fact that they are improving or not (i.e. zero relative change). In such a way, non-improving iterations lower the average and make the threshold loose its original meaning. The solution to this issue would be increasing the number of iterations to reduce the influence of non-improving ones while decreasing the threshold. However, this would lead to a more time-consuming process. Moreover, how much the threshold should be reduced is unclear. Therefore, one of the customized stopping criteria is inspired by the default one but considers only improving iterations. Thus, the process is faster and the definition of the threshold and the number of iterations to compute the average on is more straight-forward for the user. However, when the optimal solution is approached, the amount of non-improving iterations increases. The risk is that the process keeps going because there are not enough improving iterations to compute the average on. In these situations, it has 
been noticed that GA tends to create population of almost identical individuals. Therefore, the second ad hoc stopping criterion consists of terminating the optimization when a user-defined amount of individuals of the current population are identical and no improvement in the fitness function is achieved from the previous iteration. To prove the efficiency of the customized optimization algorithms with integrated memory system, a simple example with only two spans (i.e. two variables in level 1) has been considered. Results show a reduction of $66 \%$ in the computational time with no significant differences in the optimal solution. For this example and for the results shown in the rest of the paper, several tests are carried out and the following parameters are selected. Regarding the default GA and PS stopping criteria, most of the default

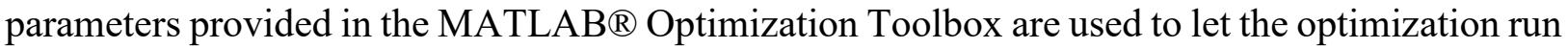
as long as possible and increase the chances of reaching the minimum. Concerning the additional GA stopping criteria, the optimization of the static system is terminated when the relative average change over 10 improving consecutive iterations is lower than $5 \%$ and/or at least $30 \%$ of the individuals of the current population are identical. During the deck dimensions optimization using PS, the process stops when the improvement in the objective function is less than $3 \%$ the starting value at the end of level 1 and the mesh size is lower than $10^{-3}$. Concerning the populations for GA algorithms, the size is 80 with 10 elite individuals and 0.7 crossover fraction. Finally, the initial mesh size for PS is 150 . Concerning the mesh size unit, it is the one of the variable the mesh is applied to. In this case, it is meters for the cross-section dimensions and meters/meters for the web inclination.

\section{3.}

\section{CASE STUDY}

The proposed procedure has been applied to make a new virgin design of an existing beam bridge crossing Norrtälje River, Sweden. The real bridge was designed in 2013 by the Swedish company ELU Konsult AB according to Eurocodes requirements.

\subsection{The built bridge}

The shape of the cross-section of the deck and the elevation of the bridge are shown in Figure 4 and Figure 7, respectively. It has five spans $(21.5+27+27+27+21.5 \mathrm{~m})$ and three foot paths with a minimum vertical clearance of $3 \mathrm{~m}$. The deck has constant width of $10 \mathrm{~m}$ except for the first span from the left and part of the second one, where it varies from $15.4 \mathrm{~m}$ to $10 \mathrm{~m}$. The total height of the deck cross-section is equal to $1150 \mathrm{~mm}$ at all mid-spans and in correspondence to the first and last supports, while it is $1650 \mathrm{~mm}$ in correspondence to the internal piers. The cantilever part of the deck is constant along the bridge and has a minimum thickness $\left(h_{3}\right)$ of 200 $\mathrm{mm}$, a maximum one $\left(h_{2}+h_{3}\right)$ of $350 \mathrm{~mm}$ and a length $\left(b_{3}\right)$ of $2690 \mathrm{~mm}$. The web inclination $\left(b_{2} / h_{1}\right)$ is constant as well and equal to 0.38 . The concrete in the superstructure is of quality $\mathrm{C} 35 / 45$, that in the substructure is $\mathrm{C} 30 / 37$ and the reinforcement is B500B. To allow a fair comparison with the optimal solution found by the software, the existing structure is slightly modified. A constant total deck width of $10 \mathrm{~m}$ all along the bridge is assumed and the reinforcement is computed with the same procedure used during the optimization. 


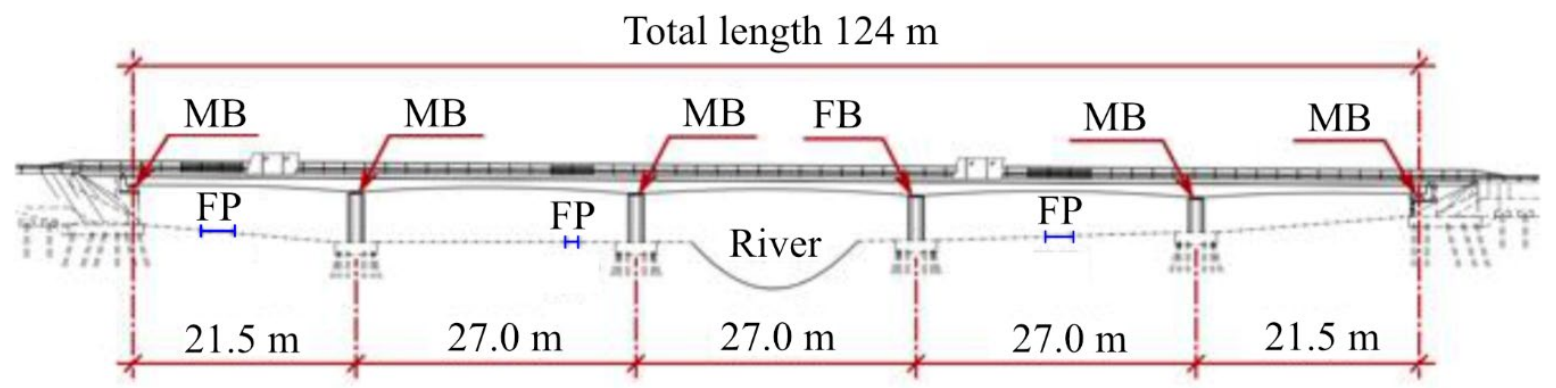

Figure 7 -Elevation of the existing bridge over Norrtälje River [32]. MB = movable bearing, $F B=$ fixed bearing, $F P=$ footpath.

\section{2}

\section{Optimal solution: results and discussion}

During the optimization of the static system, only pier locations are used as variables. Type and cost of expansion joints depend on the elongation they must accommodate. Since this cost and their environmental impact is not included in the calculation, all deck bearings are considered movable except for the one closest to the centre of the bridge. In this way, the two expansion joints at the ends of the bridge would work in the same way and thus have the same cost regardless of the final solution. Moreover, aiming at even elongations is the common practice nowadays. Concerning the penalty factor ( $\mu$ in Eq. (3)), several tests are carried out and the value $1.5 \cdot 10^{8}$ is found suitable for the formulation of the constraints and the magnitude of the objective functions.

Table 3 shows the assumed feasible ranges for the cross-section dimensions. One should remember that during level 1 the deck cross section is constant along the bridge and the dimensions are assigned by the user; except for the height of the web $\left(h_{l}\right)$ that is computed as explained in Section 2. Table 4 presents all the different values that are used as preassigned parameters in level 1 optimization. All possible combinations of these values are tried while assuming five spans as in the built bridge. The aim is studying the effect of initial cross-section dimensions on the optimal static system. Given certain sets of cross-section dimensions, the optimal solution results in a deck so tall that the requirement of minimum vertical clearance at the footpaths is not fulfilled. Therefore, no feasible solution is found. In the next paragraphs, whenever an infeasible solution for level 1 will be mentioned, it will refer to this instance.

Table 3 - Feasible ranges for the crosssection dimensions of the deck.

\begin{tabular}{cc}
\hline Dimensions & Feasible range \\
\hline$h_{3}(\mathrm{~mm})$ & $180-600$ \\
$h_{2}(\mathrm{~mm})$ & $0-500$ \\
$h_{1}(\mathrm{~mm})$ & $300-3500$ \\
$b_{3}(\mathrm{~mm})$ & $1500-2940$ \\
$b_{1}(\mathrm{~mm})$ & $500-6000$ \\
$b_{2} / h_{1}(\mathrm{~mm})$ & $0-1$ \\
\hline
\end{tabular}

Table 4 - Tested initial values for the crosssections of level 1.

\begin{tabular}{cc}
\hline Dimensions & Initial values in level 1 \\
\hline$h_{3}(\mathrm{~mm})$ & {$[200,300,400,500,600]$} \\
$b_{3}(\mathrm{~mm})$ & {$[1500,2000,2500,2900]$} \\
$h_{2}(\mathrm{~mm})$ & $5 \% b_{3}$ \\
$b_{2} / h_{1}(\mathrm{~mm})$ & {$[0,0.3,0.5,0.8,1]$} \\
\hline
\end{tabular}

The best results for both investment cost and environmental impact are found with long and thin cantilevers. To explain this, consider Figure 5: the flange does not play a significant role in the resistance of the cross-section while adding material and thus cost. Therefore, for a given 
cantilever length, its thickness should be as small as possible. Furthermore, the governing dimension for the deck stiffness is the web height. Since the total deck width is fixed, a shorter cantilever would lead to a wider web but not a much stiffer cross-section. Once again, it would result in additional material and cost without additional resistance. Results also show improvement in the performance with increasing web inclination $\left(b_{2} / h_{1}\right)$. This results from the highest bending moments being reached at the supports where the upper part of the cross-section requires higher resistance. However, it is not always possible to find feasible solutions for high values of the inclination $(0.8,1)$ in level 1 . In these cases, the web in the lower part becomes very narrow and thus the reinforcement is placed in several rows; its centre of gravity is moved upwards with a consequent reduction of the bending resistance. To increase the resistance, an even taller cross-section is necessary with the risk of not fulfilling the requirement about the minimum vertical clearance over footpaths. Therefore, it is advisable to assume intermediate values of the web inclination $(0.3,0.5)$ in level 1.

Another important result of the parametric study on the initial values of the deck cross-section concerns the relation between investment cost $(I C)$ and environmental impact $(E I)$. With the current material prices and emissions (Appendix A and Table 2), the two objective functions seem not to be conflicting. Thus, a multi-objective approach would not be necessary. Table 5 and Table 6 show results of level 1 optimization for two different deck cross sections. It can be noticed that optimizing $I C$ or $E I$ lead to similar solutions in terms of piers location and almost equal objective functions. The same behaviour is observed for other dimensions of the cross-sections. It is important to mention that values of $I C$ and $E I$ shown in this paper are obtained as explained in Section 2. In particular, $I C$ will not be the actual total investment cost of the built solution since several contributions have not been considered (e.g. rent of machineries, cost of design etc.). Values of $I C$ and EI shown in the tables should be treated as scores associated to solutions to allow ranking them. What matters the most is the relative differences/savings between solutions and not the absolute values. However, the way $I C$ and $E I$ have been formulated in this work makes them suitable objective functions for this optimization problem. Indeed, the neglected contributions would not change significantly going from one solution to another; $I C$ and $E I$ here consider only what actually differentiates a solution from another one in terms of material amount and buildability.

Based on all these considerations, the following values are assumed for the initial deck crosssection: $h_{3}=200 \mathrm{~mm}, b_{3}=2500 \mathrm{~mm}$ and $b_{2} / h_{1}=0.5$. Three possible configurations are studied for level 1: four, five and six spans. No feasible solutions are found for four spans with neither of the objective functions. Concerning the cases with five and six spans, $I C$ and $E I$ are not conflicting in the current case study: minimizing one leads to a low value of the other as well and to similar solutions. Thus, from here on, only results regarding the minimization of $E I$ will be shown. Finally, the difference in terms of $E I$ and $I C$ for the cases with five and six spans is not significant (0.2- $0.3 \%)$; therefore, in this case, the user can decide which static system to use in level 2 based on other criteria. In contrast to the case with six spans, the optimal span lengths of the case with five spans led to an almost symmetrical static system, which has been considered more pleasant from the esthetical point of view. Thus, this solution is used in level 2 and it is characterized by the following span lengths: $22.1+25.8+28.4+26+21.7 \mathrm{~m}$. 
Table 5 - Optimal static system with five spans, $h_{3}=200 \mathrm{~mm}, b_{3}=2000 \mathrm{~mm}$ and $b_{2} / h_{1}$ $=0.3$.

\begin{tabular}{ccc}
\hline Variable & Obj. Func. IC & Obj. Func. $E I$ \\
\hline$I C\left(10^{6} €\right)$ & 1.328 & 1.339 \\
$E I\left(10^{6} €\right)$ & 0.264 & 0.264 \\
Pier 1 at $(\mathrm{m})$ & 22.1 & 20.8 \\
Pier 2 at $(\mathrm{m})$ & 48.0 & 48.0 \\
Pier 3 at $(\mathrm{m})$ & 77.1 & 76.4 \\
Pier 4 at $(\mathrm{m})$ & 101.4 & 100.4 \\
\hline
\end{tabular}

Table 6-Optimal static system with five spans, $h_{3}=400 \mathrm{~mm}, b_{3}=2500 \mathrm{~mm}$ and $b_{2} / h_{1}$ $=0.8$.

\begin{tabular}{ccc}
\hline Variable & Obj. Func. IC & Obj. Func. $E I$ \\
\hline$I C\left(10^{6} €\right)$ & 1.242 & 1.245 \\
$E I\left(10^{6} €\right)$ & 0.246 & 0.246 \\
Pier 1 at $(\mathrm{m})$ & 21.2 & 20.7 \\
Pier 2 at $(\mathrm{m})$ & 48.1 & 48.0 \\
Pier 3 at $(\mathrm{m})$ & 76.6 & 77.4 \\
Pier 4 at $(\mathrm{m})$ & 102.9 & 103.3 \\
\hline
\end{tabular}

During level 2 optimization, the following variables are used: thicknesses of the cantilever $\left(h_{2}\right.$ and $\left.h_{3}\right)$, amplified inclination of the web $\left(1000 * b_{2} / h_{1}\right)$ and web height $\left(h_{1}\right)$. The web inclination is amplified in order for all the variables to have values with the same order of magnitude. In this way, the searching domain of each variable will be analysed at the same extent with the mesh applied by the PS. The total deck width is fixed, thus either the cantilever length $\left(b_{3}\right)$ or the web width $\left(2 b_{1}\right)$ can be used as variable. To understand which one is the most suitable for the problem, both cases are studied and the results of the optimization are shown in Tables 7-10. Tables 7 and 9 show the comparison between the built solution (BS) and the optimal solutions (OS) obtained with $2 b_{1}$ and $b_{3}$ as design variables, respectively. In both cases, a reduction of $8-14 \%$ on both $I C$ and $E I$ is obtained. Such results can be further improved tuning the parameters of the optimization algorithms. For instance, a progressive reduction of the initial mesh for PS from 150 to 0.150 shows an improvement in the performance: savings of $12.1 \%$ and $15.2 \%$ respectively for $I C$ and $E I$ are achieved with an initial mesh equal to 0.150 . Each complete solution is characterized by eleven cross-sections along the deck with different dimensions: one cross-section at each pier location and one at each mid-span. For the sake of brevity, concerning the dimensions in Tables 8 and 10, only highest and lowest values along the bridge are shown for the case with initial mesh of 150. All cases show large variations in the web height as expected for a continuous beam. However, the case with $2 b_{1}$ as design variable (Table 8), presents shorter sections at the supports (i.e. lower maximum values of $h_{1}$ ). Concerning the cantilever, all cases tend to make it as slender as possible as expected. However, the case with $2 b_{1}$ as design variable has longer cantilever than the others and thus steeper web inclinations (i.e. lower values). The consequence of these differences is that the performance of the optimization process with $b_{3}$ as variable (Table 9) is slightly better. The geometric differences listed above have an effect on the savings in terms of materials. It can be noticed that high savings in the reinforcement amount correspond to high saving in both $E I$ and $I C$ (Table 9). When the reinforcement amount is increased in order to reduce the concrete, the performance is poorer (Table 7). These results are a first hint of the fact that the optimization is mainly led by the reinforcement.

Figure 8 shows the variation of the quantities in Table 9 during the optimization. The vertical line represents the passage from level 1 to level 2, which needs many more generations to find the optimal solution due to the higher number of variables. All quantities are normalized with respect to the corresponding values in the first feasible solution. The trends of the investment cost and the environmental impact are similar, thus confirming the idea that the two objective functions are not conflicting. In some portions of first graph, the environmental impact shows a slightly stronger dependence on the concrete amount than the investment cost. 
Nordic Concrete Research - Publ. No. NCR 61 - ISSUE 2 / 2019 - Article 4, pp. 53-78

Table 7 -Built solution (BS) vs optimal solution (OS). $2 b_{1}$ as design variable.

\begin{tabular}{cccc}
\hline Quantity & BS & OS & Saving (\%) \\
\hline Concrete $\left(10^{3} \mathrm{~m}^{3}\right)$ & 1.08 & 0.90 & 16.91 \\
Reinf. (ton) & 252 & 230 & 8.61 \\
Form $\left(\mathrm{m}^{2}\right)$ & 1718 & 1663 & 3.18 \\
Piles $(\mathrm{m})$ & 2016 & 1848 & 8.33 \\
$I C\left(10^{6} €\right)$ & 1.206 & 1.102 & 8.65 \\
$E I\left(10^{6} €\right)$ & 0.232 & 0.205 & 11.87 \\
\hline
\end{tabular}

Table 9 - Built solution (BS) vs optimal solution (OS). b3 as design variable.

\begin{tabular}{cccc}
\hline Quantity & BS & OS & Saving $(\%)$ \\
\hline Concrete $\left(10^{3} \mathrm{~m}^{3}\right)$ & 1.08 & 1.01 & 6.86 \\
Reinf. (ton) & 252 & 201 & 20.37 \\
Form $\left(\mathrm{m}^{2}\right)$ & 1718 & 1656 & 3.62 \\
Piles $(\mathrm{m})$ & 2016 & 2016 & 0.00 \\
$I C\left(10^{6} €\right)$ & 1.206 & 1.074 & 10.92 \\
$E I\left(10^{6} €\right)$ & 0.232 & 0.201 & 13.43 \\
\hline
\end{tabular}

Table 8 - Cross-section dimensions along the bridge in the OS. $2 b_{1}$ as design variable.

\begin{tabular}{ccc}
\hline Dimensions & Range & Mean value \\
\hline$b_{3}(\mathrm{~m})$ & $2.88-2.94$ & 2.93 \\
$h_{2}(\mathrm{~mm})$ & $20-140$ & 95 \\
$h_{3}(\mathrm{~mm})$ & $180-260$ & 199 \\
$b_{2} / h_{1}(\mathrm{~mm})$ & $0-0.93$ & 0.52 \\
$h_{1}(\mathrm{~mm})$ & $0.48-1.67$ & 0.97 \\
\hline
\end{tabular}

Table 10 - Cross-section dimensions along the bridge in the OS. b3 as design variable.

\begin{tabular}{ccc}
\hline Dimensions & Range & Mean value \\
\hline$b_{3}(\mathrm{~m})$ & $2.50-2.93$ & 2.73 \\
$h_{2}(\mathrm{~mm})$ & $50-130$ & 80 \\
$h_{3}(\mathrm{~mm})$ & $180-230$ & 199 \\
$b_{2} / h_{1}(\mathrm{~mm})$ & $0.78-1$ & 0.91 \\
$h_{1}(\mathrm{~mm})$ & $0.51-1.92$ & 1.22 \\
\hline
\end{tabular}

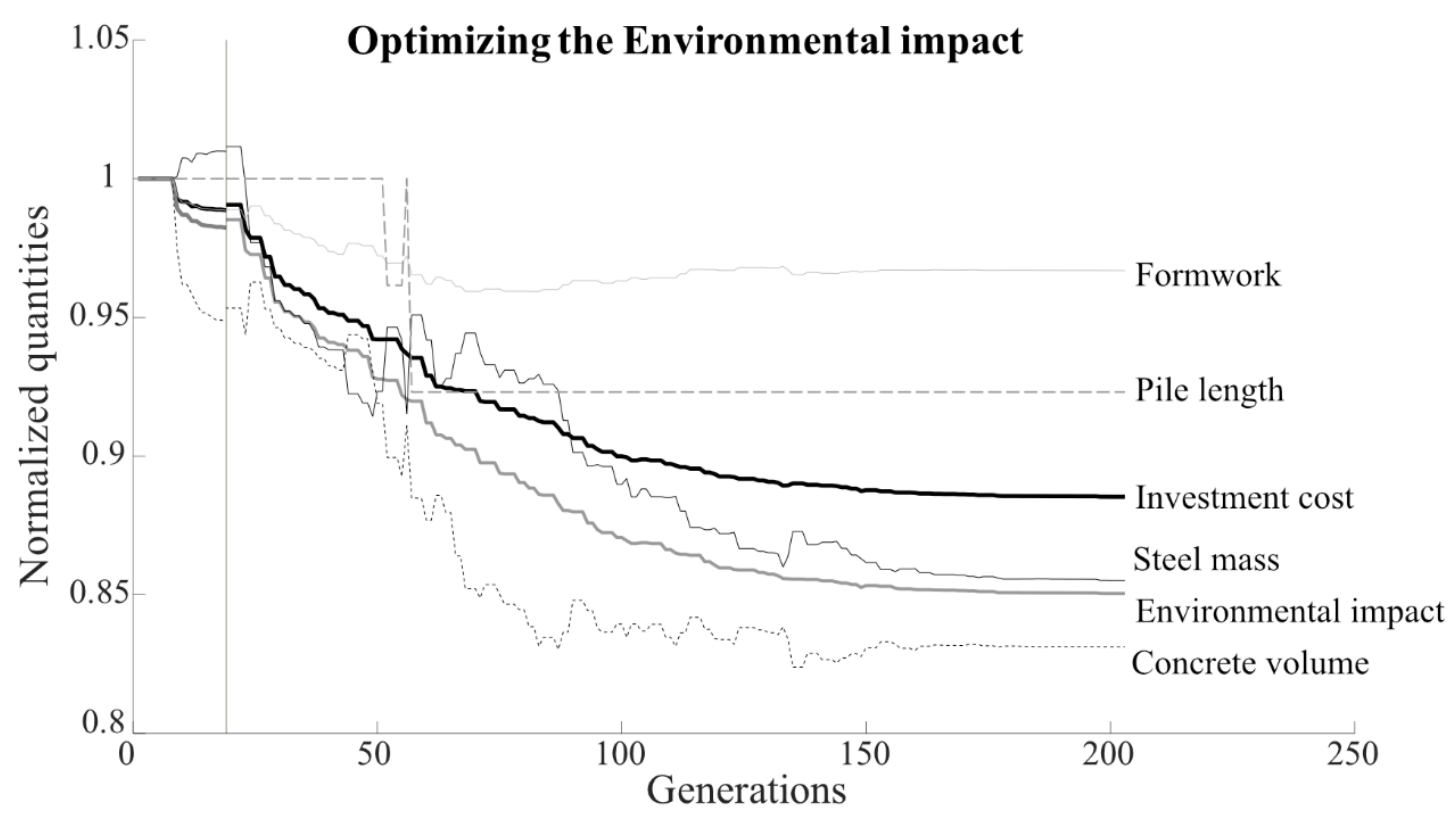

Figure 8 - Variation of material quantities, investment cost and environmental impact during the optimization. The vertical line represents the passage from level 1 to level 2.

Such result is confirmed by Figure 9 that shows the materials contribution on $E I$ and $I C$ for the optimal solution. Since only $I C$ includes form and scaffolding, to make a fairer comparison, a modified $I C$ that considers only concrete, reinforcement and RC piles has been computed. The graphs of Figure 9 clearly show that concrete has a higher impact on $E I$ than it has on $I C$. However, 
reinforcement contributes the most to both $I C$ and EI. Finally, concerning the impact categories, as expected, the highest contribution to the total environmental impact comes from the global warming, which accounts for $91 \%$ of the total impact.

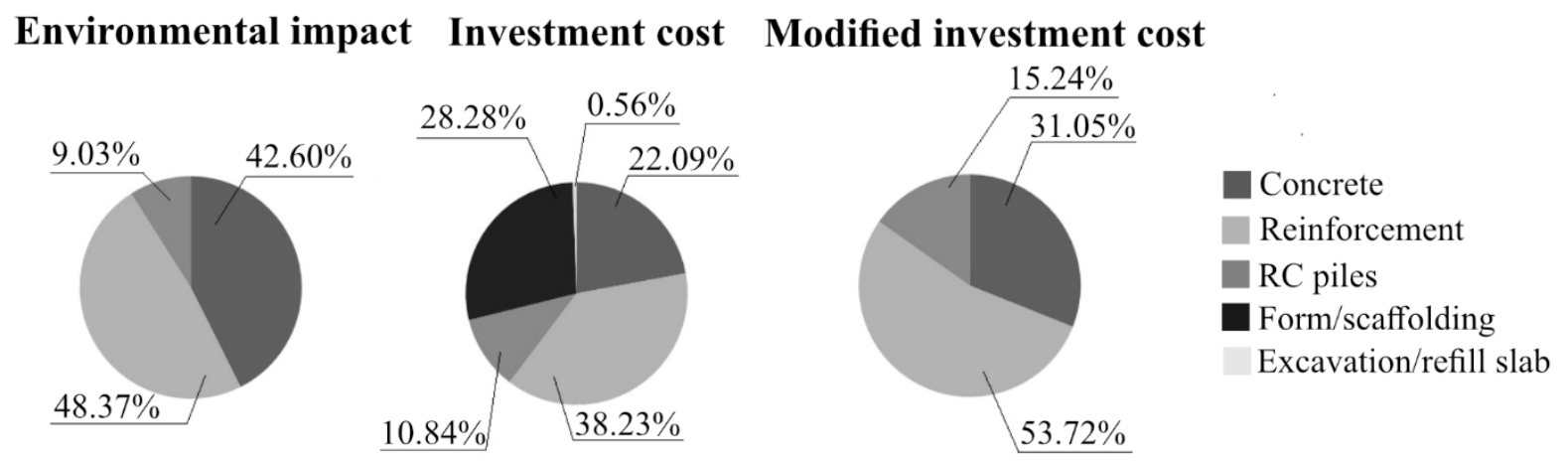

Figure 9-Materials contributions on the total investment cost, total environmental impact and modified investment cost (i.e. investment cost of only concrete, reinforcement and RC piles).

\section{3}

An easy-to-build optimal solution

The optimal solutions presented up to now are characterized by spans of diverse lengths and deck dimensions varying all along the bridge. Construction of these solutions could be time-consuming and prone to mistakes. Thus, a more buildable solution (Buildable Optimal Solution BOS) is designed based on the optimal one. Table 11 and 12 show the comparison between the built solution (BS) and the buildable optimal solution (BOS) in terms of material quantities, IC, EI and geometry. Savings higher that $10 \%$ for both investment cost and environmental impact are obtained with a solution that, compared to the built one, does not make the construction work more complex. In the particular case of Norrtälje Bridge, the built solution is not extremely far from the proposed optimal one: the main differences are in the web inclination and height. This confirms that the existing solution has been designed by experienced bridge engineers. However, it is not always the case: employing the developed design software would allow designers with any experience to find suboptimal solutions and consider investment cost and environmental impact from the early design stage

Table 11 - Built solution (BS) versus buildable optimal solution (BOS) in terms of materials quantities, investment cost (IC) and environmental impact (EI).

\begin{tabular}{cccc}
\hline Quantity & BS & BOS & Saving (\%) \\
\hline Concrete $\left(10^{3} \mathrm{~m}^{3}\right)$ & 1.08 & 0.99 & 8.87 \\
Reinf. (ton) & 252 & 207 & 17.80 \\
Form (m $\left.{ }^{2}\right)$ & 1718 & 1677 & 2.37 \\
Piles (m) & 2016 & 2016 & 0.00 \\
$I C\left(10^{6} €\right)$ & 1.206 & 1.083 & 10.17 \\
$E I\left(10^{6} €\right)$ & 0.232 & 0.202 & 12.88 \\
\hline
\end{tabular}


Nordic Concrete Research - Publ. No. NCR 61 - ISSUE 2 / 2019 - Article 4, pp. 53-78

Table 12 - Comparison between built solution (BS) and buildable optimal solution (BOS).

\begin{tabular}{ccc}
\hline Variable & BS & BOS \\
\hline Span lengths $(\mathrm{m})$ & 21.527272721 .5 & 22.525 .52825 .522 .5 \\
Bearings & MB MB MB FB MB MB & MB MB FB MB MB MB \\
$b_{3}(\mathrm{~m})$ & 2690 & 2750 \\
$h_{2}(\mathrm{~mm})$ & 150 & 100 \\
$h_{3}(\mathrm{~mm})$ & 200 & 180 \\
$b_{2} / h_{1}(\mathrm{~mm})$ & $0.38\left(h_{1} \approx 2.6 b_{2}\right)$ & $0.91\left(h_{1} \approx 1.1 b_{2}\right)$ \\
& 800 in the field of spans 1,3 and 5 & 1100 in the field of spans 1,3 and 5 \\
$h_{1}(\mathrm{~mm})$ & 800 in the field of spans 2 and 4 & 600 in the field of spans 2 and 4 \\
& 800 at the external supports & 1100 at the external supports \\
& 1300 at all internal supports & 1700 at all internal supports \\
\hline
\end{tabular}

Results of the case study in Section 3 show the potential of integrating the current design practice with the use of the developed software. However, the purpose of this work goes beyond it and aims at producing graphs and guidelines for bridge engineers. An initial attempt is presented in this section: the aim is to suggest the optimal number of spans for a given total bridge length.

For a given total bridge length, a set of possible number of spans is determined such that span lengths are in the range $8-40 \mathrm{~m}$. A constant bridge height of $5 \mathrm{~m}$ and minimum vertical clearance of $3 \mathrm{~m}$ all along the bridge are assumed. No infeasible regions for the piers are considered. For each number of spans, the optimal pier location to minimize IC or EI is determined. During the optimization, the deck cross-section is that used for level 1 optimization of the bridge over Norrtälje River. Figure 10 and 11 shows the results of this process for total bridge lengths in the range 25-200 $\mathrm{m}$. On the vertical axis, the graphs show the value of the best objective function divided by the total area of the deck and then normalized with respect to the case with total length of $25 \mathrm{~m}$ and 2 spans. On the horizontal axis there is the total bridge length. For one value of bridge length and given number of spans, one point in the graph (i.e. one optimal solution) is found. Using these points and linear interpolation, for each number of spans in the range 2-7, it is possible to determine the curve which relates the minimum objective function and the total bridge length. Comparing these curves, one can determine the optimal number of spans for a given total bridge length. The dotted vertical lines in Figure 10 and 11 represent the intersections between these curves, i.e. the bridge lengths at which there is a change in the optimal number of spans. Table 13 summarizes the results of the comparison between these curves for both Figure 10 and 11; intersection values are rounded at $5 \mathrm{~m}$.

As the comparison between Figure 10 and Figure 11 shows, the different objective functions do not affect the results significantly. This confirms the hypothesis of non-conflicting investment cost and environmental impact. It is also interesting to notice that the shorter the bridge, the clearer the difference in terms of $E I$ and $I C$ between solutions with different number of spans. Accordingly, in the range of length $95-130 \mathrm{~m}$, the solutions with five, six and seven spans do not differ that much. Indeed, at the end of level 1, for the bridge over Norrtälje River, it was not possible to choose between five and six spans only based on the optimization result. Finally, the optimal number of spans of Table 13 suggests spans shorter than $30 \mathrm{~m}$. This is in accordance with the current practice in many European countries where pre-stressed concrete is used instead of reinforced concrete for longer spans. 
Finally, sensitivity analyses on preassigned parameters have been performed for total lengths up to $100 \mathrm{~m}$. Steel unit price has been studied in the range $20 \%-200 \%$ of the initial price in Appendix A: the range of variation of the intersections of Figure 10 is limited to $4 \mathrm{~m}$. Concerning the environmental impact, unit emissions of concrete and reinforcement in Table 2 have been gradually decreased by $50 \%$ separately: the range of variation of the intersections of Figure 11 is limited to $5 \mathrm{~m}$. In both cases, results of Table 13 do not change significantly.

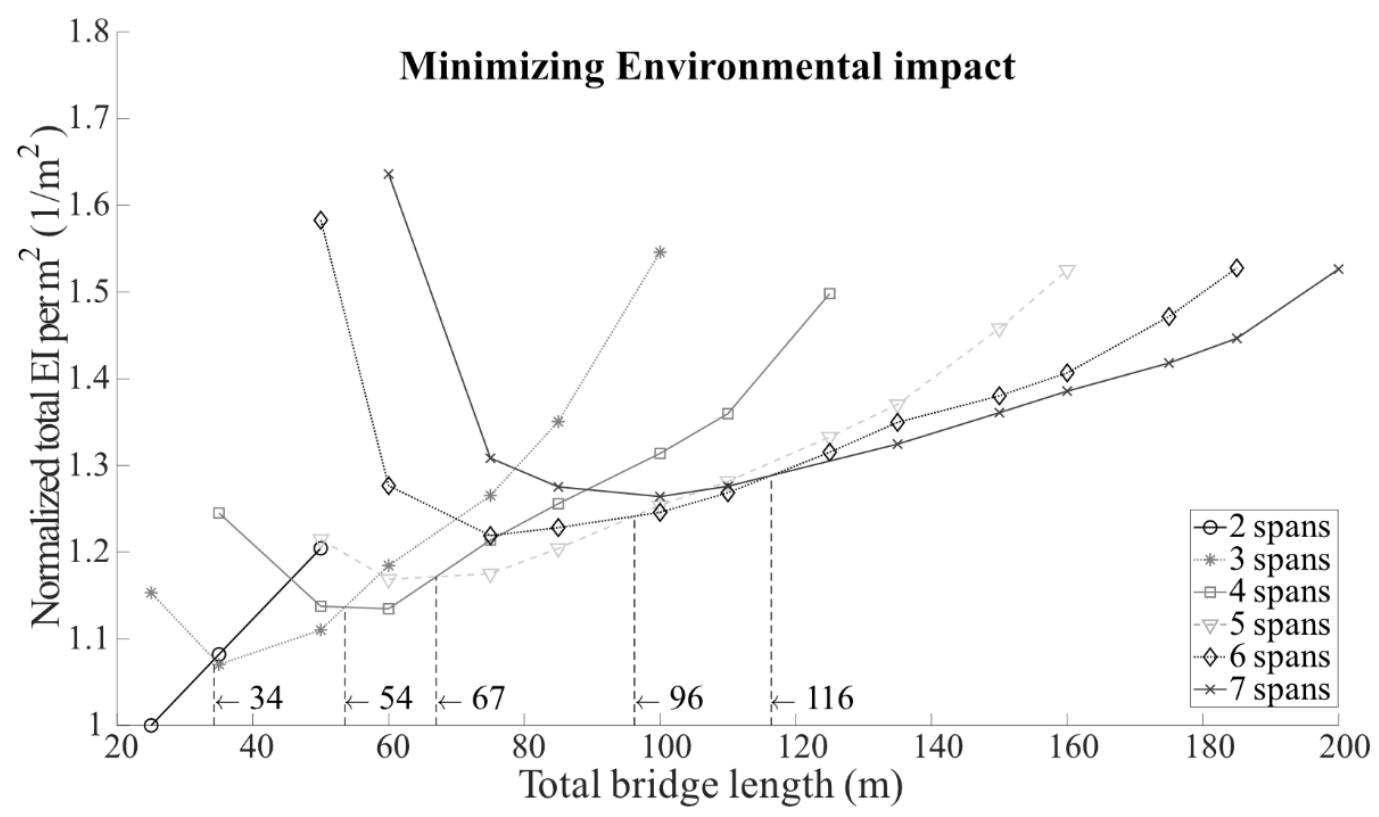

Figure 10 - Normalized environmental impact per square meter of deck for several bridge lengths and span numbers.

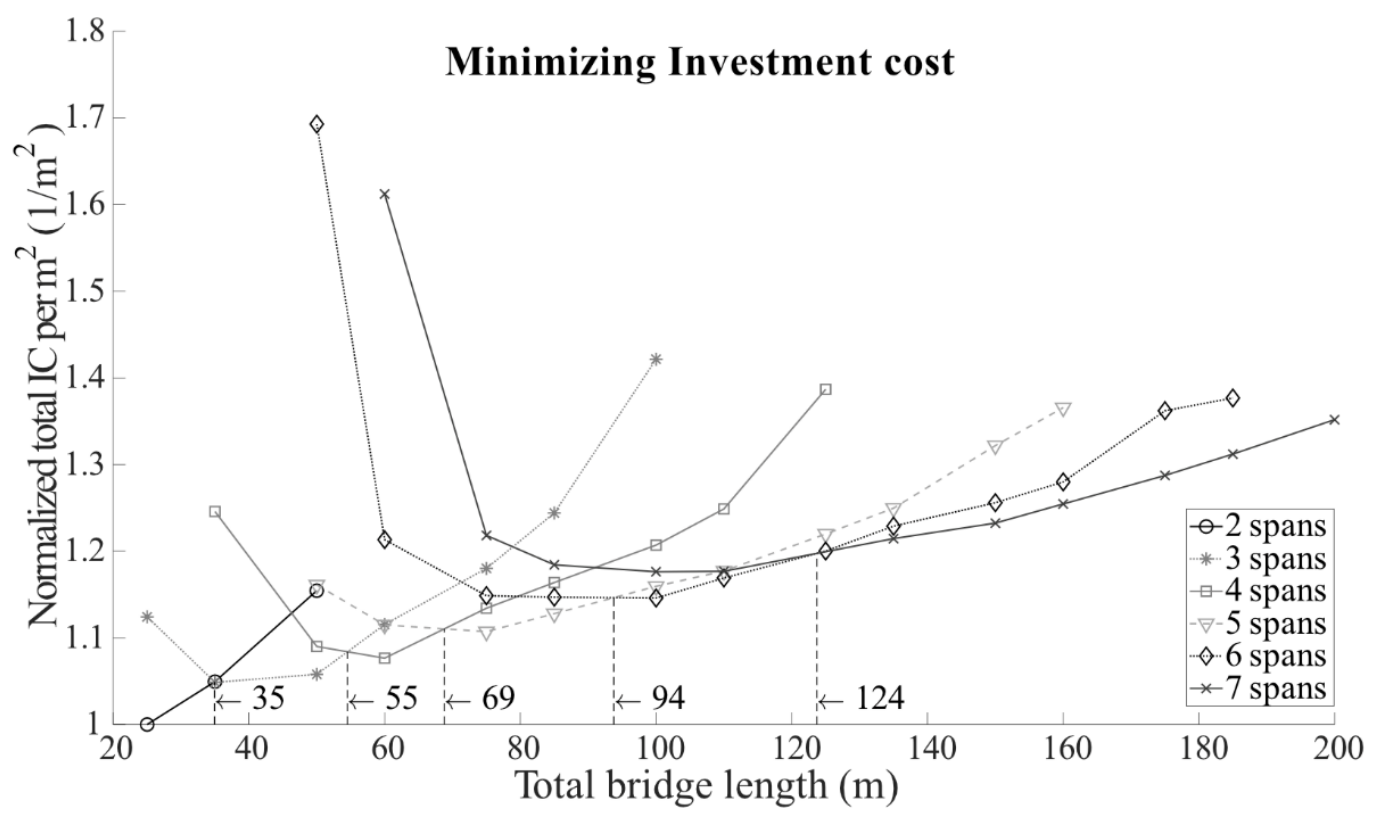

Figure 11 - Normalized investment cost per square meter of deck for several bridge lengths and span numbers. 
Nordic Concrete Research - Publ. No. NCR 61 - ISSUE 2 / 2019 - Article 4, pp. 53-78

Table 13 - Optimal number of spans to minimize environmental impact and investment cost per deck square meter.

\begin{tabular}{cc}
\hline Total bridge length $(\mathrm{m})$ & Optimal number of spans \\
\hline $25-35$ & 2 \\
$35-55$ & 3 \\
$55-65$ & 4 \\
$65-95$ & 5 \\
$95-130$ & $5-6-7$ \\
$130-200$ & $\geq 7$ \\
\hline
\end{tabular}

5.

\section{CONCLUSIONS}

In this paper, a two-steps automatic design procedure for road beam bridges is presented. It finds the solution that minimizes the investment cost or the environmental impact of the bridge, while fulfilling all requirements of Eurocodes. In the first step, given the soil morphology and the two points the bridge has to connect, it selects the optimal number of spans, type of connection piersdeck and pier locations taking into account any obstacle the bridge has to cross. In the second and final step, it finds the optimal dimensions of the deck cross-sections. Furthermore, the required reinforcement for the deck is designed in a detailed way: given the bar diameters, spacing and cover, the total amount of bars and the exact layout are determined. A software for the application

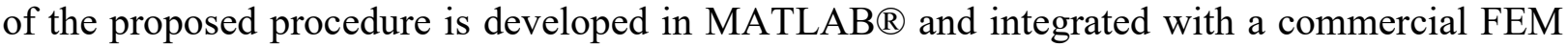
software for the structural analysis of bridges. An application for the detailed design of reinforcement in RC sections is developed as well. Pattern Search provided in MATLAB ${ }^{\circledR}$ Optimization Toolbox is used as optimization algorithms together with a modified version of Genetic Algorithm. A memory system is integrated to make the process faster and treat continuous variables in a discrete way. In this paper, the software is tested to produce a virgin design of an existing structure. Several analyses have been carried out in this case study leading to the following results.

Solutions that combine structural optimization and buildability can be designed based on the results of the optimization procedure. In the presented case study, the comparison between the proposed solution and the built one leads to savings in the range $10-15 \%$ on investment cost (IC) and environmental impact $(E I)$ without increasing the complexity of the structure.

The promising results obtained in this case study suggest that the software would be a useful tool for bridge engineers with any level of experience. Moreover, its deployment would significantly reduce the duration of the design phase, while allowing the consideration and quantification of the environmental impact from the early design stage.

Furthermore, the software presented in this paper can be used as a tool to produce diagrams and guidelines for bridge designers. In the present paper a first attempt to produce these guidelines is included as well. The optimal number of spans for $10 \mathrm{~m}$ wide, $5 \mathrm{~m}$ high beam bridges are suggested for length in the range $25-200 \mathrm{~m}$. 
Finally, within the limitations of this work, $I C$ and $E I$ seem not to be conflicting; therefore, a complex multi-objective approach should not be needed. Indeed, despite the environmental impact being more sensitive to variations of concrete amount than the investment cost, the quantity leading the optimization process is the reinforcement amount for both objective functions. A multi-objective optimisation could be needed for other bridge types than the one studied here or when considering other life cycle stages or design variables. A cradle-to-gate approach is used here for $E I$, while $I C$ includes only material cost and labour cost during construction. Future work should extend the analysis to include the whole life-cycle of the bridge and consider durability of materials. Finally, the choice of materials and materials quality or deck type would also represent an interesting addition to the proposed design method.

\section{ACKNOWLEDGMENTS}

The authors want to express their gratitude to KTH Royal Institute of Technology, the Swedish consulting company ELU Konsult AB and the Swedish Transport Administration (Trafikverket) for financial and technical support of this project.

\section{REFERENCES}

1. UN environment and International Energy Agency: "Towards a zero-emission, efficient, and resilient buildings in construction sector. Global status report 2017".

2. Worrell E, Price L, Martin N, Hendrik C \& Meida L O: "Carbon dioxide emissions from the global cement industry". Annual Review of Energy and the Environment, Vol. 26, No. 1, 2001, pp. 303-329.

3. Paya-Zaforteza I, Yepes V, Hospitaler A \& Gonzalez-Vidosa F: " $\mathrm{CO}_{2}$-optimization of reinforced concrete frames by simulated annealing”. Engineering Structures, Vol. 31, No. 7, 2009, pp. 1501-1508.

4. Aguilar R J, Movassaghi K, Brewer J A \& Porter J C: “Computerized optimization of bridge structures”. Computers \& Structures, Vol. 3, No. 3, 1973, pp. 429-442.

5. Wills J. (Transport and Road Research Laboratory): "A mathematical optimization procedure and its application to the design of bridge structure". Wokingham, UK, 1973.

6. Surtees J O \& Tordoff D: "The Application of Direct Search Optimisation to Structural Design". Journal of Constructional Steel Research, Vol. 1, No. 2, 1981, pp. 39-44.

7. Guan H, Chen Y J, Loo Y C, Xie Y M \& Steven G P: "Bridge topology optimization with stress, displacement and frequency constraints". Computers and Structures, Vol. 81, No. 3, 2003, pp. 131-145.

8. Xie Y M, Zuo Z H, Huang X, Black T \& Felicetti P: "Application of topological optimization technology to bridge design”. Structural Engineering International, Vol. 24, No. 2, 2014, pp. 185-191.

9. Perea C, Alcala J, Yepes V, Gonzalez-Vidosa F \& Hospitaler A: "Design of reinforced concrete bridge frames by heuristic optimization". Advances in Engineering Software, Vol. 39, 2008, pp. 676-688.

10. Yavari M S, Pacoste C \& Karoumi R: "Structural optimization of concrete slab frame bridges considering investment cost". Journal of Civil Engineering and Architecture, Vol. 10, 2016, pp. 982-994. 
11. Yavari M S, Du G, Pacoste C \& Karoumi R: "Environmental impact optimization of reinforced concrete slab frame bridges". Journal of Civil Engineering and Architecture, Vol. 11, 2017, pp. 313-324.

12. Hassan M M: "Optimization of stay cables in cable-stayed bridges using finite element, genetic algorithm, and B-spline combined technique". Engineering Structures, Vol. 49, 2013, pp. 643-654.

13. Lee T Y, Kim Y H \& Kang S W: "Optimization of tensioning strategy for asymmetric cablestayed bridge and its effect on construction process". Structural and Multidisciplinary Optimization, Vol. 35, 2008, pp. 623-629.

14. Lute V, Upadhyay A. \& Singh K K: "Computationally efficient analysis of cable-stayed bridge for GA-based optimization". Engineering Aplications of Artificial Intelligence, Vol. 22, No. 4-5, 2009, pp. 750-758.

15. Kusano I, Baldomir A, Jurado J A \& Hernández S: "Probabilistic optimization of the main cable and bridge deck of long-span suspension bridges under flutter constraint" Journal of Wind Engineering and Industrial Aerodynamics, Vol. 146, 2015, pp. 59-70.

16. Lonetti P \& Pascuzzo A: "Optimum design analysis of hybrid cable-stayed suspension bridges". Advances in Engineering Software, Vol. 73, 2014, pp. 53-66.

17. Cao H, Qian X, Chen Z \& Zhu H: "Layout and size optimization of suspension bridges based on coupled modelling approach and enhanced particle swarm optimization". Engineering Structures, Vol. 146, 2017, pp. 170-183.

18. Kaveh A, Maniat M \& Arab Naeini M: "Cost optimum design of post-tensioned concrete bridges using a modified colliding bodies optimization algorithm". Advances in Engineering Software, Vol. 98, 2016, pp. 12-22.

19. Rana S., Islam N., Ahsan R. \& Ghani S.N.: "Application of evolutionary operation to the minimum cost design of continuous prestressed concrete bridge structure". Engineering Structures, No. 46, 2013, pp. 38-48.

20. Jahjouh M M, Arafa M H \& Alqedra M A: "Artificial Bee Colony (ABC) algorithm in the design optimization of RC continuous beams". Structural and Multidisciplinary Optimization, Vol. 47, No. 6, 2013, pp. 963-979.

21. Akin A \& Saka M P: “Optimum Detailed Design of Reinforced Concrete Continuous Beams using the Harmony Search Algorithm". Proceedings, Tenth International Conference on Computational Structures Technology, Universidad Politecnica di Valencia, Spain, September 2010.

22. Pedro R L, Demarche J, Miguel L F F \& Lopez R H: "An efficient approach for the optimization of simply supported steel-concrete composite I-girder bridges". Advances in Engineering Software, Vol. 112, 2017, pp. 31-45.

23. García-Segura T \& Yepes V: "Multiobjective optimization of post-tensioned concrete boxgirder road bridges considering cost, CO2 emissions, and safety". Engineering Structures, Vol. 125, 2016, pp. 325-336.

24. Yepes V, Martí J V \& García-Segura T: "Cost and CO2 emission optimization of precastprestressed concrete U-beam road bridges by a hybrid glowworm swarm algorithm". Automation in Construction, Vol. 49, 2015, pp. 123-134.

25. Orcesi A, Cremona C \& Ta B: "Optimization of design and lyfe-cycle management for steel-concrete composite bridges". Structural Engineering International, Vol. 28, No. 2, 2018, pp. 185-195.

26. Aydin Z \& Ayvaz Y: "Overall cost optimization of prestressed concrete bridge using genetic algorithm”. KSCE Journal of Civil Engineering, Vol. 17, No. 4, 2013, pp. 769-776.

27. Wight J \& MacGregor J: "Reinforced concrete mechanics and design", 5th Edition. Pearson Prentice Hall, Upper Saddle River, New Jersey, USA, 2008, 1112 pp. 
28. Hassanain M A \& Loov R E: "Cost optimization of concrete bridge infrastructure". Canadian Journal of Civil Engineering, Vol. 30, 2003, pp. 841-849.

29. Srinivas V \& Ramanjaneyulu K: "An integrated approach for optimum design of bridge decks using genetic algorithms and artificial neural networks". Advances in Engineering Software, Vol. 38, No. 7, 2007, pp. 475-487.

30. European Committee for Standardization (CEN): "EN 1991-2. Eurocode 1: Actions on structures - Part 2: Traffic loads on bridges". Bruxelles, Belgium, 2003.

31. European Committee for Standardization (CEN): "EN 1992-2. Eurocode 2: Design of concrete structures - Part 2: Concrete bridges - Design and detailing rules". Bruxelles, Belgium, 2005.

32. El Mourabit S: "Optimization of Concrete Beam Bridges-Development of Software for Design Automation and Cost Optimization". MSc Thesis, KTH Royal Institute of Technology, Dept. of Civil \& Architectural Engineering, Div. of Structural Engineering \& Bridges, Stockholm, Sweden, 2016, 41 pp.

33. Griva I, Nash S G \& Sofer A: "Linear and nonlinear optimization". Society for Industrial and Applied Mathematics, Philadelphia, Pennsylvania, USA, 2009).

34. Yang X S: "Nature-Inspired Optimization Algorithms". Elsevier, Amsterdam, The Netherlands, 2014.

35. Goedkoop M J, Heijungs R, Huijbregts M, De Schryver A, Struijs J \& Van Zelm R: "ReCiPe 2008 - A life cycle impact assessment method which comprises harmonised category indicators at the midpoint and the endpoint level", First edition (version 1.08) Report I: Characterisation", Netherlands, 2013.

36. Swiss Center For Life Cycle Inventories: "Ecoinvent Database v2.01". Dübendorf, Switzerland, 2008.

37. PRéConsultants: "SimaPro 7.1.5", 2008.

38. Bauman H \& Tillman A M: "The Hitch Hiker's Guide to LCA: An orientation in LCA methodology and application". Studentlitteratur AB, Sweden, 2006.

39. Flower D J M \& Sanjayan J G: "Greenhouse gas emissions due to concrete manufacture". The International Journal of Life Cycle Assessment, Vol. 12, No. 5, 2007, pp. 282-288

40. Du G \& Karoumi R: "Life cycle assessment of a railway bridge: comparison of two superstructure designs". Structure and Infrastructure Engineering, Vol. 9, No. 11, 2013, pp. 1149-1160.

41. Finnveden G, Eldh P \& Johansson J: "Weighting in LCA based on ecotaxes - Development of a mid-point method and experiences from case studies". The international journal of Life Cycle Assessment, Vol. 11, 2006, pp. 81-88.

42. Ahlroth S \& Finnveden G: "Ecovalue08 - A new valuation set for environmental systems analysis tools". Journal of Cleaner Production, Vol. 19, 2011, pp. 1991-2003.

43. Finnveden G., Håkansson C. \& Noring M.: "A new set of valuation factors for LCA and LCC based on damage cost - Ecovalue 2012”. Proceedings, 6th International Conference on Life Cycle Management, Gothenburg, Sweden, August 2013, pp. 197-200.

44. Swedish National Road Administration: "TRVR Bro 11. Trafikverkets tekniska råd Bro", publ nr 2011:086, Borlänge, Sweden, 2011. (In Swedish).

45. Pacoste $\mathrm{C}, \mathrm{Plos} \mathrm{M} \&$ Johansson $\mathrm{M}$ : "Recommendations for finite element analysis for the design of reinforced concrete slabs". Report, KTH, ELU \& Chalmers, Stockholm \& Göteborg, Sweden, 2012.

46. The MathWorks Inc., R2016b: "MATLAB and Optimization Toolbox", Massachusetts, USA, 2016. 
Nordic Concrete Research - Publ. No. NCR 61 - ISSUE 2 / 2019 - Article 4, pp. 53-78

\section{APPENDIX A}

\section{UNIT PRICES}

Unit prices $\left(C_{m}\right)$ of material used for the calculation of the material cost as part of the total investment cost (Eq. (5), Section 2.2).

\begin{tabular}{ll}
\multicolumn{2}{c}{ Table A.1 - Unit prices for piles. } \\
\hline Pyle type & $C_{\text {pile }}(€ / \mathrm{m})$ \\
\hline Concrete piles SP1 & 45 \\
Concrete piles SP2 & 55 \\
Concrete piles SP3 & 70 \\
Steel core piles $\phi 90$ & 350 \\
Steel core piles $\phi 100$ & 425 \\
Steel core piles $\phi 120$ & 475 \\
Steel core piles $\phi 150$ & 550
\end{tabular}

Table A.2 - Unit prices for different materials and elements.

\begin{tabular}{lll}
\hline Material & $C_{m}$ & Unit \\
\hline Concrete C32/40 & $170^{1}$ & $€ / \mathrm{m}^{3}$ \\
Concrete C35/45 & $180^{1}$ & $€ / \mathrm{m}^{3}$ \\
Concrete C50/60 & $200^{1}$ & $€ / \mathrm{m}^{3}$ \\
Reinforcement & 900 & $€ / \mathrm{ton}$ \\
Formwork: deck with distance from the ground up to 5 m & $100^{2}$ & $€ / \mathrm{m}^{2}$ \\
Formwork: deck with distance from the ground of 5-7 m & $125^{2}$ & $€ / \mathrm{m}^{2}$ \\
Formwork: wing walls & 40 & $€ / \mathrm{m}^{2}$ \\
Formwork: piers consisting in two columns of constant diameter & 30 & $€ / \mathrm{m}^{2}$ \\
Formwork: piers consisting in one stepped column & 70 & $€ / \mathrm{m}^{2}$ \\
Formwork: foundation slabs & 20 & $€ / \mathrm{m}^{2}$ \\
\hline
\end{tabular}

${ }^{1}$ It includes $20-30 \mathrm{~km}$ of transportation.

${ }^{2}$ It includes scaffolding. 


\section{APPENDIX B}

\section{CONSTRUCTABILITY COEFFICIENTS}

Constructability coefficients $\left(k_{m}^{e}\right)$ used for the calculation of the labour cost as part of the total investment cost (Eq. (6), Section 2.2).

Table B.1 - Constructability coefficients for concrete.

\begin{tabular}{ll}
\hline Element & Constructability coefficient for concrete \\
\hline Deck: cross-section type $1^{1}$ & 1 \\
Deck: cross-section type $2^{1}$ & 1.1 \\
Deck: cross-section type $3^{1}$ & 1.3 \\
Wing walls & 2 \\
Piers consisting in two columns of constant diameter & 1 \\
Piers consisting in one stepped column & 2 \\
Foundation slab & 1
\end{tabular}

Table B.2 - Constructability coefficients for reinforcement.

Element Constructability coefficient for
reinforcement

Deck: cross-section type $1^{1}$

Deck: cross-section type $2^{1}$

Deck: cross-section type $3^{1} \quad 1.25$

Wing walls with constant thickness $\quad 1.75$

Wing walls with variable thickness 2

Wing walls: extra multiplying factor for thickness $<40 \mathrm{~cm} \quad 1.2$

Wing walls: extra multiplying factor for thickness: 40-60 cm $\quad 1.1$

Piers consisting in two columns of constant diameter $\quad 1.2$

$\begin{array}{ll}\text { Piers consisting in one stepped column } & 1.7\end{array}$

Foundation slab 1

${ }^{1}$ Figure 3.

Table B.3-Constructability coefficients for formwork.

\begin{tabular}{ll}
\hline Element & Constructability coefficient for formwork \\
\hline Deck with distance from the ground up to $5 \mathrm{~m}$ & 2 \\
Deck with distance from the ground of 5-7 m & 2.3 \\
Wing walls with constant thickness & 2 \\
Wing walls with variable thickness & 3 \\
Piers consisting in two columns of constant diameter & 1.2 \\
Piers consisting in one stepped column & 2.5 \\
Foundation slab & 1 \\
\hline
\end{tabular}


Nordic Concrete Research - Publ. No. NCR 61 - ISSUE 2 / 2019 - Article 4, pp. 53-78

\section{APPENDIX C}

\section{ECOVALUE-WEIGHTING SET}

Weighting factor $\left(w_{k}\right)$ used for the calculation of the environmental impact (Eq. (9), Section 2.2).

Table C.1 - Ecovalue weighting set [47].

\begin{tabular}{ll}
\hline Impact category & Weighting \\
\hline Global warming & $0.285 € / \mathrm{kg} \mathrm{CO}_{2}$-eq \\
Terrestrial acidification & $3 € / \mathrm{kg} \mathrm{SO}_{2}$-eq \\
Freshwater eutrophication & $67 € / \mathrm{kg} \mathrm{P}$ \\
\hline
\end{tabular}

